\title{
Determination of five amides in food contact materials by GC/MS
}

\author{
Zhen Cheng ${ }^{\mathrm{a}}$, Zhexiang Zou ${ }^{\mathrm{b}}, \mathrm{Xi}_{\text {Tang }}^{\mathrm{b}}$, Minshi Chen ${ }^{\mathrm{b}}$, Huajian Liu ${ }^{\mathrm{b}}$, Jiajia Lai, \\ Yang Jie ${ }^{\mathrm{a}}$, Xiaojing $\mathrm{Li}^{\mathrm{b}^{*}}$,
}

${ }^{a}$ College of Biological Sciences and Technology, Fuzhou University, Fujian Key Laboratory of Marine Enzyme Engineering, Fuzhou, Fujian 350116, China

${ }^{\mathrm{b}}$ Technical Centre of Fujian Entry-Exit Inspection and Quarantine Bureau, Fuzhou 350001, China

Keywords: Food Contact Materials; Amides; GC/MS

Abstract: A method based on gas chromatography-mass spectrometry (GC/MS) was developed and validated for qualitative determination of five amides in food contact materials. The five amides are acrylamide, methacrylamide, caprolactam, oleamide and stearamide. The linear detection ranges of the method were $5-100 \mu \mathrm{g} / \mathrm{mL}$ and the recoveries were $79.3 \%-101.6 \%$. Detection limits of five amides were $0.08-1.0 \mu \mathrm{g} / \mathrm{mL}$ and the relative standard deviations (RSDs) were in the range of 2.5 $-10.0 \%$.

\section{Introduction}

Amides are important starting monomers and additives for plastics, paper, coatings and adhesives. However, when entering the body, these substances may cause damage to nerves, kidneys, and liver, and even are potential carcinogens. For example, toxic caprolactam mainly acts on the central nervous system, which can cause substantial damage to organs like the brain stem. Acrylamide is recognized as a Class 1B carcinogen by EU regulations [1].

Juana Bustos et al. [2] explore the migration of caprolactam from nylon to food simulants by HPLC. Juliana S. Félix et al. [3] used GC-FID to investigate the migration of caprolactam and polyamide from PA films to food simulants. Zhang Cong et al. [4] determined the contents of acrylamide, methacrylamide, N-methylolacrylamide, and $\mathrm{N}$-(methoxymethyl)methacrylamide in food simulants by UPLC-MS/MS. Fang Ning [5] used gas chromatography-mass spectrometry to explore the migration of oleamide, stearamide, erucamide and behenamide in water, $3 \%$ ethanol solution, $4 \%$ ethanol solution and lipid food simulants.

The purpose of this paper is to develop a high-throughput and rapid test method for the detection of common amides in food contact materials. This method will be applied to study the migration of amides from the food contact materials

\section{Materials and Apparatus}

\section{Materials}

Arylamide, methacrylamide, and caprolactam standards were obtained from Chem Service (America). Stearamide standards were obtained from TCR (Canada). Oleamide standards were purchased from Tokyo Kasei Kogyo Co. Ltd. (Tokyo, Japan).

\section{Apparatus}

GC analyses were performed on Agilent 7890A system (Agilent Technologies, Palo Alto, CA, USA). Agilent HP-5MS column ( $30 \mathrm{~m} \times 0.32 \mathrm{~mm}, 0.25 \mu \mathrm{m}$ particle size $)$ from Agilent Technologies was used for the separation. 
The separated compounds were detected with an Agilent 5975C mass spectrometer (Agilent Technologies, Palo Alto, CA, USA).

\section{Results and discussion}

\section{Method Development}

This article uses gas chromatography tandem mass spectrometry to detect five common amides in food contact materials. The separation of various amides is shown in Figure 1.

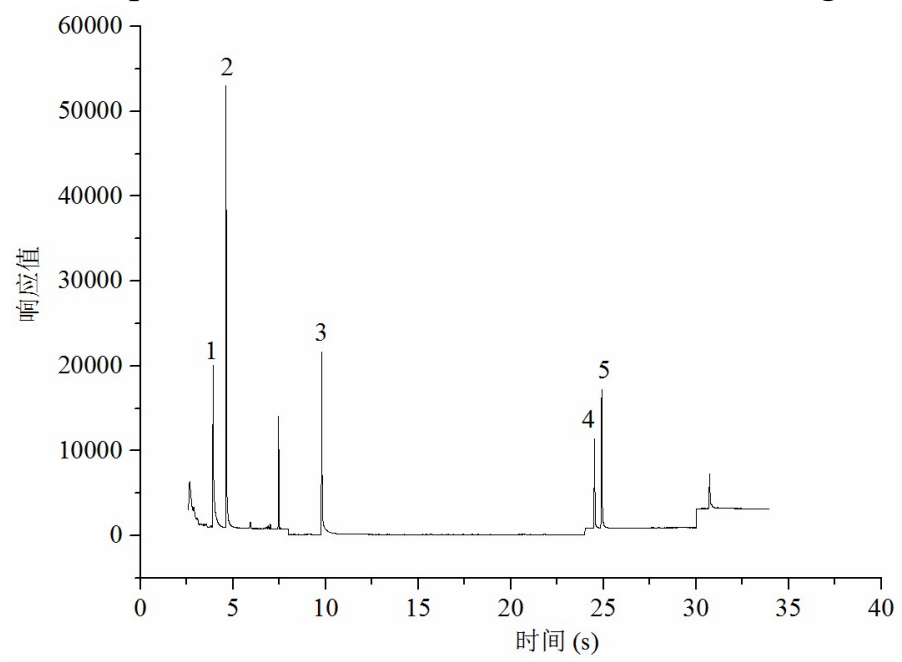

Fig. 1. Total ion current chromatogram of standard compounds

1: acrylamide, 2: methacrylamide, 3 :caprolactam, 4:oleamide, 5: stearamide

In the gas chromatograph, injection volume is $1 \mu \mathrm{l}$, the carrier gas is helium, and the split ratio is $5: 1$. For the oven program, initial temperature is $60{ }^{\circ} \mathrm{C}$, holding for $1 \mathrm{~min}$, then $10 / \mathrm{min}$ to $200^{\circ} \mathrm{C}$ for $0 \mathrm{~min}$, and finally raise to $270^{\circ} \mathrm{C}$ at $5{ }^{\circ} \mathrm{C} / \mathrm{min}$, maintained $5 \mathrm{~min}$.

In the mass spectrometer, we choose the highest abundance of product ion and two extra product ion with a signal $\geqslant 10 \%$ as qualitative ions. The qualitative characteristic ions of various amides are shown in Table 1.

Table 1 Qualitative Characteristic Ions of Five Amide Species By GC/MS

\begin{tabular}{|c|c|c|c|}
\hline Number & Sample & CAS & $\begin{array}{c}\text { Qualitative } \\
\text { Characteristic Ions }\end{array}$ \\
\hline 1 & Acrylamide & $073-6-1$ & $44,55,71^{*}$ \\
\hline 2 & Methacrylamide & $079-39-0$ & $41,69,85^{*}$ \\
\hline 3 & Caprolactam & $105-60-2$ & $55,85,113^{*}$ \\
\hline 4 & Oleamide & $301-02-0$ & $41,59 *, 72$ \\
\hline 5 & Stearamide & $124-26-5$ & $41,59 *, 72$ \\
\hline
\end{tabular}

* the highest abundance of product ion in GC/MS

\section{Evaluation of Analytical Methods}

Identification of the target compounds was accomplished by comparing the retention times and mass spectrum information against those of standard compounds. The linear ranges, limits of detection, and recoveries were obtained and shown in Table 2. 
Table 2. Linear Range, Correlation Coefficient (r), LODs and recoveries obtained for five investigated compounds in food contact materials

\begin{tabular}{|c|c|c|c|c|}
\hline Compound & $\begin{array}{c}\text { Linear range } \\
(\mu \mathrm{g} / \mathrm{mL})\end{array}$ & $\begin{array}{c}\text { Correlation } \\
\text { coefficient } \\
(\mathrm{r})\end{array}$ & $\begin{array}{c}\text { LODs } \\
(\mu \mathrm{g} / \mathrm{mL})\end{array}$ & Recovery \\
\hline Acrylamide & $5 \sim 100$ & 0.9999 & 1.00 & $79.3 \% \sim 87.3 \%$ \\
\hline Methacrylamide & $5 \sim 100$ & 0.9992 & 0.08 & $81.5 \% \sim 90.4 \%$ \\
\hline Caprolactam & $5 \sim 100$ & 0.9997 & 0.12 & $90.6 \% \sim 98.7 \%$ \\
\hline Oleamide & $5 \sim 100$ & 0.9988 & 0.09 & $92.5 \% \sim 101.6 \%$ \\
\hline Stearamide & $5 \sim 100$ & 0.9979 & 0.15 & $91.7 \% \sim 100.8 \%$ \\
\hline
\end{tabular}

a the limits of detection (LODs) were calculated based on single-to-noise ratio $(\mathrm{S} / \mathrm{N} \geq 3$ ) at lowest concentration which could be detected

\section{Conclusion}

A high-throughput and sensitive method has been developed to determine five amides in food contact materials by $\mathrm{GC} / \mathrm{MS}$ in this paper.

\section{Acknowledgements}

This project was financially supported by Key Project of Fujian Provincial Science and Technology program (No. 2018Y0084) and Science Project of Technical Centre of Fujian Entry-Exit Inspection and Quarantine Bureau（No. FK2017-JS006）.

\section{References}

[1] Regulation(EC) No.1272/2008 of the European parliament and of the council. Official Journal of European Union, 2008-12-31.

[2] Bustos J, Sendón R, Sánchez J J, et al. Migration of $\varepsilon$-caprolactam from nylon cooking utensils: validation of a liquid chromatography-ultraviolet detection[J]. European Food Research \& Technology, 2009 , 230 (2) : 303-313

[3] Félix J S, Manzoli J E, Padula M, et al. Evaluation of Different Conditions of Contact for Caprolactam Migration from Multilayer Polyamide Films into Food Simulants[J]. Packaging Technology \& Science, 2014, 27(6):457-466.

[4] Zhang C, Xian Y, Guo X, et al. Isotope Internal Standard Method for Determination of Four Acrylamide Compounds in Food Contact Paper Products and Food Simulants by Ultra-High Performance Liquid Chromatography Tandem Mass Spectrometry[J]. Food Analytical Methods, 2016, 9(7):1895-1903.

[5] Fang Ning, Wang Zijian, Zhao Jinsong, et al. Determination of 4 kinds of migration of lubricant in food contact materials by gas chromatography-mass spectrometry[J]. Chinese Journal of Food Hygiene, 2016, 28(3): 319-322. 